\section{DYSENTERY : ITS SUCCESSFUL TREAT- MENT BY IPECACUANHA IN LARGE DOSES; ALSO BY A NEW REMEDY.}

\section{By ARCHIBALD HEWAN, M.D. EDIN.}

Havisg had very large opportunity of witnessing the cha. racter and ravages of this terrible disease during a residence of several years as medical missionary at Old Calabar, on the West Coast of Africa, and having employed several remedies as means of cure with varying results, I feel bound to declare my testimony in favour of the ipecacuanha treatment, as being not only the least disappointing, but, when rightly used, attended with the most certain success. This treatment has been more than once brought to the notice of the profession in the columns of THE LANCET, and I beg to add my humble name to the list of its advocates, while I urge, with all my heart, its use.

It was while battling with a very prolonged and peculiarly severe attack of the malady in a native that I saw for the first time an account of the successful use of this medicine in large doses in India. I had then been so frequently disappointed with the common treatment by astringents, opiates, \&c., that I had very nearly lost all confidence in them. I may mention, in passing, that I had found gentle laxatives, followed by small doses of rhubarb and quinine, do most good. But now I was glad to have an agent that promised such good and complete results. I put it into practice at once, and the result was most gratifying.

The natives themselves have no certain means of cure. For the most part they use enemata composed of the fresh leaves and barks of certain plants, having more or less astringency about them. But their mode of administration is rough, irritating, and very awkward. Very many die. Tbose who recover do so slowly and very tediously. The disease is common luring the wet season, which begins about June, and is concurrent with the bringing in of the new yams, Indian corn, and other products at that time.

Fearing such an alarming disease, the chiefs and the better class of the community avoid eating new fruits for a considerable time after they have been first gathered in. Indeed it is one of the unmistakable signs of a gentleman, about which they are very particular, to be able to live on his old year's stock for some time after his less distinguished neighbours have had recourse to the new. A chief of any importance will not eat new year's produce till the ceremonies by way of thanksgiving have been duly celebrated. And this celebration does not take place till the chief's old stores are nearly empty, by which time new year's stock has been pretty largely stored and seasoned.

The Europeans who come to the place are mainly sailors, or, at least, connected with the shipping, and live on board the vessels lying in the river. They suffer in common with the natives from eating new yams, while they, moreover, are liable to dysentery as the result of exposure, fatigue, or other irregularities.

The loss of my case-book in the confusion and accidents of moving and travel, containing the details of my cases, makes it impossible for me to give a full account of them; but, perhaps, this is of little moment, as they would doubtless have occupied too much space for the columns of THE LANCET. It may, therefore, be enough if I say that the value of the remedy so please $\mathrm{L}$ me in its results that I never thought afterwards of seeking for any other means of cure. Nor can I bring to my recollection any case in which the remedy failed; whereas from time to time before that I had the pain and anxiety of seeing one and another patient sink and die under the usual remedies, and with the conjoint skill and care of my medical brethren along with me.

But in urging this remedy I must not forget to state what is at once apparent, and that is the huge and ugly dose. One drachm of powdered ipecacuanha, mixed in water, forms a grim draught to look at. Not every patient would consent to take it, unless as a last resource. Smaller doses, from half a drachm downwards, have been tried, but in my experience they are much less effective. Hore frequent doses have in this. way to be given, and nausea kept up unnecessarily. How ever, an intelligent and skilful medical friend of mine, then on the Coast, now in Liverpool, speaks highly of the smaller dose in a case of chronic form of the complaint that came under his hands on board the steamer on his way homeward from the Coast.

Whether so large a dose as one drachm is necessary in this country I have not yet had an opportunity of satisfying myself. It is a matter worthy of investigation; and if a concentrated tincture of the root could be employed, the large dose would literally become a small matter.

So far as I can recollect I did not find that acute attacks yielded so readily to the large dose given at the onset. A native of Sierra Leone, a carpenter, aged thirty, was attacked. He was working on my house at the time, so that be sought relief at once. Thinking to cut the matter short, I gave a full doseone drachm - of the drug; but the system seemed altogether in too irritable and excited a state. Mild aperients and sedatives, such as aconite, would, I think, have suited this case better at the first. He recovered more slowly than several others did.

I pass on to the new remedy. This is a discovery made by Mr. Kerr, surgeon, of Galt, Canada West, and is fully reported in the Edinburgh Medical Journal for June, 1865, and, if $\mathbf{I}$ mistake not, in some subsequent numbers of that journal. It was while enjoying the beautiful results of the ipecacuan treat. ment that I was called to attend the infant daughter of one of my fellow missionaries. She had suffered now and again from diarrhœea during dentition. At length the diarrhœa took on a dysenteric character. All the usual remedies were tried, but failed. The ipecacuan treatment remained. But what size of a dose should be given to so young a patient was the question, and not an easy one, to settle. All at once her father, intensely anxious, recollected a packet of medicine for dysentery a kind friend of his had given him when he was starting for the Coast. The nature of the remedy was then unknown to me, but as Mr. Robb had entire contidence in his friend who gave it to him, and as the case was desperate, I could not withhold my full consent to its administration. Full instructions were written upon it. With much concern I watched the case from day to day. The result was cheering. From the time the first dose was given, or very soon after, the child fell into a quiet and comfortable sleep, such as it had not had for many a day before. It soon completely recovered, and is now living in Scotland with its parents, a vigorous and healthy child.

The remedy, as discovered by Mr. Kerr, is a composition of several plants, and at first sight may seem a very unscientific one. But as Mr. Kerr, in his interesting paper, which is worth reading, shows that he went to work on a scientific basis, spent five or six years in working out his plan before coming to a conclusion, and that conclusion a satisfactory one, as alleged by those who have adopted it, it is, in my humble opinion, worth a careful trial as a means of cure in this dire disease. And $I$ the more gladly take notice of it in comparison with the ipecacuanha treatment which I have been advocating, for whereas in the good results from ipecacuan you have the preliminary horror of the dose, like results are to be obtained from this new composite remedy without any sickening disgust.

To quote from Mr. Kerr's paper: "Its constituents, when the investigation was concluded, were as follows:-Four officinal-viz., opium, stramonium, dulcamara, digitalis ; three non-officinal, Sium lineare, Cicuta maculata, Conio-selinum canadense. All are more or less narcotic, and digitalis, dulcamara, and Sium lineare are also diuretic...... Without opium the combination is slightly aperient, promotes sleep, and, according to experience gained in dysentery and other diseases, heals ulceration of the mucous membrane." After some further interesting remarks, Mr. Kerr gives details of cases which were cured in lis hands as well as in those of other practitioners. They are too lengthy for quotation. So also are the details I have received from friends who have used the remedy, and who speak in the highest terms of its value, as having saved the lives of patients who seem to be fast sinking under other more usual remedies.

From these, I trust not too brief details, as well as from my own experience abroad, and in a recent case here, $I$ feel bound to advocate and to publish this new remedy, while I also try to make the value of the ipecacuanha treatment, if possible, better known.

Minera-street, Eaton-square, June, 1868.

* Mr. Kerr's remedy, prepared according to his formula, is to be had at Duncan and Flockhart's, chemists, Ediriburgh, and Murdock's, chemist, Glasgow 